\title{
Extracranial Head and Neck Schwannomas: An Institutional Experience
}

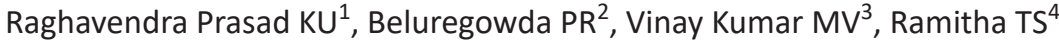

\begin{abstract}
Extracranial schwannomas of head and neck domain are rare neoplasms. Most of the times, these tumors occur as asymptomatic neck swellings which masquerade to cervical lymphadenopathy, carotid body tumors, bronchial cyst, vallecular cyst. We present ten cases of head and neck schwannomas who have been treated and followed up between June 2006 to march 2020 in the department of otorhinolaryngology of Hassan Institute of Medical Sciences, Hassan, Karnataka State, India. These patients have been retrospectively reviewed. The main aim of the study is to know the $\mathrm{NOO}$ (nerve of origin) preoperatively and on table. Also to know the unusual sites of schwannoma in head and neck domain.The age group is between $10 y$ rs to $50 y$ s and female predominance of $50 \%$ in our study.Seven patients presented with neck swelling and three patients with pressure symptoms. Pre-operative diagnosis is mainly on clinical suspicious. Radiological imaging like CT scan/MRI may be helpful in diagnosis. FNAC is adjunctive tool for diagnosis. Among 10 patients nerve of origin could make out in 7 patients. Three from sympathetic, three from vagus and one from Internal Laryngeal nerve. In three patients nerve of origin could not make out. Intracapsular dissection of the tumor with preservation of nerve of origin is most recent common modality of treatment. Neurological deficit after tumor excision is common in large tumor excision. Early recognition and treatment is best for preservation of the nerve of origin.

Keywords: Extracranial, Nerve of origin (NOO), Schwannoma, Single institution.

International Journal of Head and Neck Surgery (2021): 10.5005/jp-journals-10001-1443
\end{abstract}

\section{INTRODUCTION}

Schwannomas are benign tumors originating from perineural Schwann cells which produce myelin sheath. 'Schwannoma arise from any nerve like peripheral nerve, autonomic nerves, and all cranial nerves except olfactory and optic nerve which are devoid of myelin sheath. ${ }^{2}$ It is reported that $25-45 \%$ of extracranial schwannomas occurs in head and neck. Ten percent of the schwannomas that occur in head and neck generally originate from vagus and sympathetic nerve. ${ }^{3}$ Four to five percent of schwannomas involve nasal cavity and paranasal sinuses.

Extracranial head and neck schwannomas typically present as an asymptomatic neck swelling., ${ }^{1,3}$ Diagnosis of head and neck schwannomas is always suspicious in nature. Fine needle aspiration cytology (FNAC) is conclusive in $50-60 \%$ of cases. ${ }^{4}$ Radiological investigation such as CT scan /MRI scan helpful to locate the anatomical position, extension, and sometimes the nerve of origin (NOO). ${ }^{5}$ Definite diagnosis of the tumor is always by postoperative histopathological examination.

Growth of tumors occurs annually from 2.5 to $3 \mathrm{~mm}$. Schwannomas grows in eccentric pathway. As it enlarges it can compress the maternal nerve fibers, which grow over the tumor capsule. As it enlarges, the nerve fibers splays and becomes thinner (Fig. 1).

Neurofibroma also has origin from perineurium and linked inseparable from NOO. Nerve of origin should be known preoperatively in major nerve involvement, by means of clinical as well as radiological investigation. ${ }^{5}$

Schwannomas are radioresistant; hence, surgery is the main modality of treatment.

Surgery may include complete excision and nerve grafting, intracapsular dissection with nerve preservation and debulking of the tumor. Debulking of the tumor has high recurrence rate. Intracapsular dissection is the preferred treatment. If the tumor
${ }^{1-4}$ Department of Otorhinolaryngology, Hassan Institute of Medical Sciences, Hassan, Karnataka, India

Corresponding Author: Raghavendra Prasad KU, Department of Otorhinolaryngology, Hassan Institute of Medical Sciences, Hassan, Karnataka, India, Phone: +91 9845793876, e-mail: prasadusha45@gmail.com

How to cite this article: KU RP, PR B, MV V K, et al. Extracranial Head and Neck Schwannomas: An Institutional Experience. Int J Head Neck Surg 2021;12(3):101-105.

Source of support: Nil

Conflict of interest: None

is larger in size, even with intracapsular dissection it is difficult to preserve the nerve integrity. Hence, patients should be informed about postoperative neurological deficit.

\section{Aims and Овjectives}

- To evaluate the unusual sites of schwannoma considering its NOO.

- To assess the accuracy of CT/FNAC findings with postoperative biopsy.

- To assess the preoperative NOO and NOO on table.

\section{Materials and Methods}

Ten patients of head and neck schwannomas who have been treated at our department in our institution (Hassan Institute of Medical Sciences, Hassan, Karnataka) between June 2006 and March 2020 were reviewed, those cases which were confirmed as schwannomas postoperatively. This study in accordance with institutional ethical committee. Our institution is located in a district place having a population of 1.50-2.0 lakh. Patients age, sex, presenting symptoms and signs, anatomical location of 

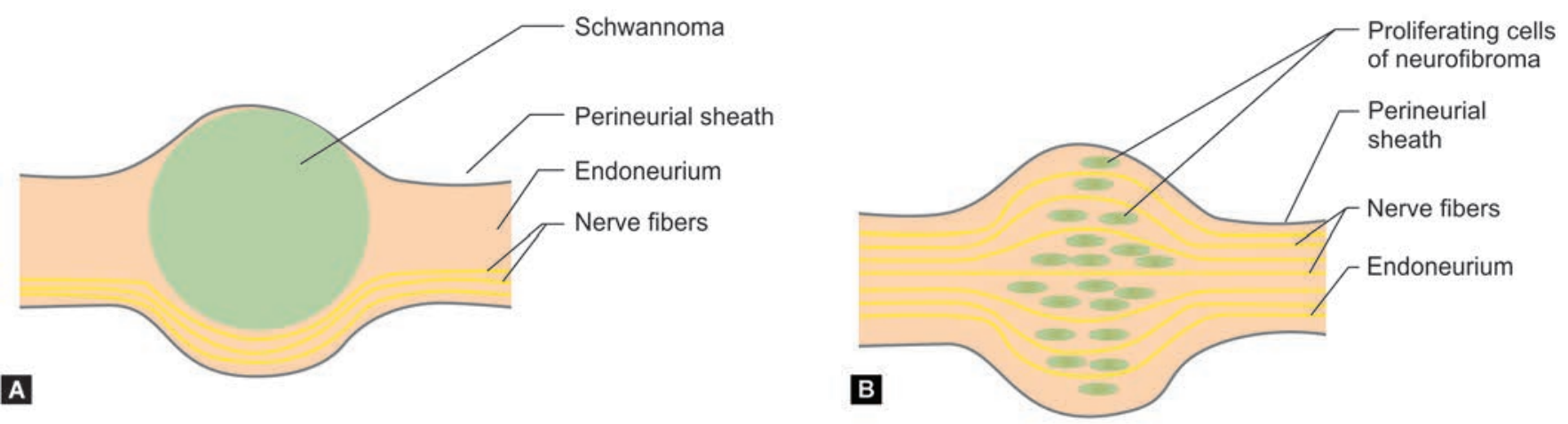

Figs 1A and B: Presentation of schwannoma and neurofibroma: (A) Schwannoma within nerve; (B) Neurofibroma within nerve

Table 1: Age, sex, and presenting signs and symptoms

\begin{tabular}{|c|c|c|c|}
\hline Pattient no. & Age (years) & Sex & Presenting signs and symptoms \\
\hline 1 & 20 & $\mathrm{~F}$ & $\begin{array}{l}\text { Foreign body sensation throat, left posterior part of tonsils pushed medially: } 3 \text { months } \\
\text { No external obvious swellings }\end{array}$ \\
\hline 2 & 10 & $\mathrm{~F}$ & Asymptomatic neck swelling left upper part of neck: 6 months \\
\hline 3 & 40 & $\mathrm{~F}$ & Asymptomatic neck swelling right upper part of neck: 6 months \\
\hline 4 & 20 & $\mathrm{~F}$ & Asymptomatic swelling left upper part of neck $7 \times 4 \mathrm{~cm}$ extending up to the level of hyoid bone: 2 years \\
\hline 5 & 40 & M & Asymptomatic swelling right upper part of neck: 2 years \\
\hline 6 & 36 & M & Asymptomatic swelling left upper part of neck below mandible: 2 years \\
\hline 7 & 50 & M & $\begin{array}{l}\text { Left nasal obstruction: } 3 \text { months } \\
\text { Mass in left nasal cavity: } 3 \text { months }\end{array}$ \\
\hline 8 & 2 & M & Asymptomatic swelling left posterior triangle neck-middle part: 2 months \\
\hline 9 & 18 & $\mathrm{~F}$ & Dysphagia, progressive dyspnoea, snoring, mass in larynx: 6 months \\
\hline 10 & 35 & M & Asymptomatic neck swelling right upper part of neck below mandible: 5 years \\
\hline
\end{tabular}

Notes: Age distribution: 10-50 yrs; Asymptomatic swelling: 7; Female:Male 5:5; Obstructive symptoms: 3

the tumor, investigation modality, surgical approach, operative findings, histopathological examination of tumor, and outcome after surgery data had been collected.

The presence of antoni A or B indicates histologic pattern to confirm schwannomas. The absence of nuclear pleomorphism, mitosis, and invasiveness noted to mainly rule out metastatic pattern. Sometimes myxoid, cystic degeneration were noted in long-standing schwannoma cases.

\section{Results}

Ten patients of head and neck were identified. The study population consist of five women and five men, with an average age of 28 years (range 10-50 years). Usual age at presentation is from 30 to 50 years except in one case in extreme age of 10 years, which is a rare occurrence. All had solitary schwannomas and none of them were from neurofibromas.

Seven patients presented with asymptomatic neck swellings and three patients with symptoms of blood pressure such as nasal obstruction, foreign body sensation, respiratory distress, and dysphagia. Out of ten patients one presented with dysphagia, dyspnoea, and snoring with no neck swelling. That patient was diagnosed as having laryngeal schwannoma.

Table 1 shows epidemiological data, clinical features, and duration of symptoms. Out of ten patients, preoperative diagnosis of nerve sheath tumor was made in in only one patient because of the previous experience. Two patients were diagnosed as having cervical lymphadenopathy, one patient with parapharyngeal tumor, one patient with carotid body tumor and nasal fibroma, and one patient with vallecular cyst. Only one patient was clinically diagnosed as having nerve sheath tumor (10\%).

All patients except one undergone $\mathrm{CT}$ scan as the radiological investigation. CT scan was not been done to one patient because of excision biopsy for reactive lymphadenopathy. FNAC was done to nine patients which identified as nerve sheath tumor in five patients. Patient number nine which presented as mass in the supraglottic area undergone incisional biopsy after tracheostomy. Incision biopsy came as schwannoma.

Table 2 shows early diagnosis and investigations. Out of 10 cases, $\mathrm{NOO}$ can be made out in 6 cases by radiological examination. Nerve of origin is mainly in three vagus and three sympathetic chain. In one case which is laryngeal schwannoma, NOO could be internal laryngeal nerve. In other three cases NOO could not be revealed. Figure 2 shows dissection of the sympathetic schwannoma.

Vagus or sympathetic nerve of origin is mainly differentiated by the displacement of carotid and Internal Jugular Vein by the tumor. Tumors arising from vagus nerve, displace internal jugular vein laterally and carotid artery medially and tumor arising from sympathetic nerve displace internal jugular vein and carotid artery anterolaterally. CT scan of the patient number 4 in which tumor displaced both carotid artery and jugular vein anterolaterally without separating them.

In all cases, the tumor was completely resected surgically by intracapsular dissection. The approach to the surgery is mainly by 
Table 2: Initial diagnosis and investigations

\begin{tabular}{|c|c|c|}
\hline Patient no & Initial diagnosis & Investigation \\
\hline 1 & $\begin{array}{l}\text { Parapharyngeal tumor } \\
\text { left side }\end{array}$ & $\begin{array}{l}\text { CT scan neck (plain and contrast): } 4 \times 2 \mathrm{~cm} \text { oval shaped nonenhanced mass in the poststyloid } \\
\text { compartment. } \\
\text { FNAC (oral): spindle cell neoplasm }\end{array}$ \\
\hline 2 & $\begin{array}{l}\text { Left cervical } \\
\text { lymphadenopathy }\end{array}$ & $\begin{array}{l}\text { CT scan neck: } 3.5 \times 2.6 \times 4.2 \mathrm{~cm} \text { soft tissue mass suprahyoid level pushed carotid and IJV } \\
\text { anterolaterally. } \\
\text { FNAC: spindle cell neoplasm }\end{array}$ \\
\hline 3 & $\begin{array}{l}\text { Right carotid body } \\
\text { tumor }\end{array}$ & $\begin{array}{l}\text { CT scan neck (plain and contrast): heterogeneous mass seen right anterior triangle pushing carotid } \\
\text { artery anterolateral and pharynx medially. } \\
\text { FNAC: cervical lymphadenopathy }\end{array}$ \\
\hline 4 & Left nerve sheath tumor & $\begin{array}{l}\text { CT scan neck (plain and contrast): well-defined hypoattenuated mass at left cervical spine measuring } \\
6 \times 4.8 \mathrm{~cm} \text { displacing IJV carotid artery anterolaterally and pharynx medially. } \\
\text { FNAC: spindle cell neoplasm }\end{array}$ \\
\hline 5 & $\begin{array}{l}\text { Left cervical } \\
\text { lymphadenopathy }\end{array}$ & $\begin{array}{l}\text { CECT Neck: A well-defined heterogeneous soft tissue mass measuring about } 5 \mathrm{~cm} \times 3 \mathrm{~cm} \text {, carotid } \\
\text { artery anteromedially, and IJV anterolaterally. } \\
\text { FNAC: reactive cervical lymphadenopathy }\end{array}$ \\
\hline 6 & $\begin{array}{l}\text { Left submandibular } \\
\text { tumor }\end{array}$ & $\begin{array}{l}\text { CECT: well-defined poststyloid parapharyngeal area pushing carotid anteromedially and IJV } \\
\text { anterolaterally. } \\
\text { FNAC: spindle cell neoplasm }\end{array}$ \\
\hline 7 & $\begin{array}{l}\text { Left nasal soft tissue } \\
\text { mass }\end{array}$ & $\begin{array}{l}\text { CECT: homogenous smooth soft tissue mass seen left nasal cavity at nasal vestibule. } \\
\text { FNAC: fibromyoma }\end{array}$ \\
\hline 8 & $\begin{array}{l}\text { Left cervical } \\
\text { lymphadenopathy }\end{array}$ & $\begin{array}{l}\text { FNAC: reactive cervical lymphadenopathy } \\
\text { Excisional biopsy: spindle cell neoplasm }\end{array}$ \\
\hline 9 & Vallecular cyst & $\begin{array}{l}\text { CECT: solid cystic lesion noted left paraglottic space extending up to the vallecula. } \\
\text { Incisional biopsy after tracheostomy shows schwannoma } \\
\text { Laryngeal schwannoma }\end{array}$ \\
\hline 10 & $\begin{array}{l}\text { Right nerve sheath } \\
\text { tumor }\end{array}$ & $\begin{array}{l}\text { CECT: homogeneous smooth soft tissue mass which pushes the carotid artery and IJV anterolaterally. } \\
\text { FNAC spindle cell neoplasm }\end{array}$ \\
\hline
\end{tabular}

Note: Inference: FNAC showed conclusive diagnosis in 5 of 10 cases (50\%)

Table 3: Nerve of origin, treatment, and follow-up

\begin{tabular}{|c|c|c|}
\hline $\begin{array}{l}\text { Patient } \\
\text { no }\end{array}$ & Nerve of origin & Treatment and follow-up \\
\hline 1 & Not known & $\begin{array}{l}\text { Complete excision, no neurological deficit } \\
4 \text { years follow-up }\end{array}$ \\
\hline 2 & $\begin{array}{l}\text { Sympathetic } \\
\text { chain }\end{array}$ & $\begin{array}{l}\text { Complete excision, no neurological deficit } \\
4 \text { years follow-up }\end{array}$ \\
\hline 3 & $\begin{array}{l}\text { Sympathetic } \\
\text { chain }\end{array}$ & $\begin{array}{l}\text { Complete excision, no neurological deficit } \\
3 \text { years follow-up }\end{array}$ \\
\hline 4 & $\begin{array}{l}\text { Sympathetic } \\
\text { chain }\end{array}$ & $\begin{array}{l}\text { Complete excision, no neurological deficit } \\
\text { follow-up: 3years }\end{array}$ \\
\hline 5 & Vagus nerve & $\begin{array}{l}\text { Complete excision, left vocal cord palsy } \\
\text { follow-up: } 2 \text { years }\end{array}$ \\
\hline 6 & Vagus nerve & $\begin{array}{l}\text { Complete excision, no neurological deficit } \\
\text { follow-up: } 2 \text { years }\end{array}$ \\
\hline 7 & Not known & $\begin{array}{l}\text { Complete excision, no neurological deficit } \\
\text { follow-up: } 2 \text { years }\end{array}$ \\
\hline 8 & Not known & $\begin{array}{l}\text { Complete excision, no neurological deficit } \\
\text { follow-up: } 1 \text { year, } 6 \text { months, and follow-up } \\
\text { continued }\end{array}$ \\
\hline 9 & $\begin{array}{l}\text { Internal } \\
\text { laryngeal } \\
\text { nerve }\end{array}$ & $\begin{array}{l}\text { Complete excision, no neurological deficit } \\
\text { follow-up } 1 \text { year and follow-up continued }\end{array}$ \\
\hline 10 & Vagus nerve & $\begin{array}{l}\text { Complete excision, no neurological deficit } \\
\text { Follow up: } 3 \text { months and follow-up } \\
\text { continued }\end{array}$ \\
\hline
\end{tabular}

Note: Nerve of origin: 3 sympathetic chain, 3 vagus and 1 internal laryngeal nerve and 3 not known transverse cervical approach except in two cases. In patient no. 7 tumor was excised through anterior rhinoscopy. In patient no. 9 suprahyoid pharyngotomy was done and excised the laryngeal schwannoma. Table 3 shows the NOO and postoperative nerve of deficit.

In our case series, there were no neurological deficit except in one patient who developed left vocal cord palsy even after intracapsular dissection and nerve fascicles grafting. This patient is on follow-up for a period of 2 years. Patient no. 9, who underwent suprahyoid pharyngotomy, had Ryle's tube feeding for 8 days and tracheostomy tube for 5 days. Laryngeal edema persisted for 4 weeks. Then on laryngoscopy examination, function of both vocal cords were normal. None of the patients had neurological deficit of cervical sympathetic chain. None of the patient had recurrence or features of malignancy.

\section{Discussion}

Schwannomas was first identified by Virchow in 1908 and later reported by Vercoy in $1910 .{ }^{6}$ Neurogenic tumors of head and neck arise from neural crest cells which differentiate into nerve sheath cells and sympathoblast. Schwannomas and neurofibromas arise from schwann cells. ${ }^{7}$ Schwannomas arises exclusively from schwann cells, while neurofibroma comprises a mixture of three cells schwann cells, perineural cells, and perineural fibroblasts. Hence neurofibromas are inseparable from NOO. $^{8}$

Head and neck schwannomas always present as lateral neck swelling, and rarely they present with symptoms of pressure. ${ }^{9}$ In our case series, 7 out of 10 patients presented with asymptomatic neck swellings (Table 1 and Fig. 3). Among unusual sites we encountered one from laryngeal schwannoma and another from 
nasal cavity schwannoma. One patient presented with unilateral tonsillar enlargement.

In this study group, preoperative diagnosis had different differential diagnosis like cervical lymphadenopathy, submandibular tumor, vallecular cyst, parapharyngeal tumor. As schwannomas are rare, preoperative clinical diagnosis is difficult. Furthermore, these tumors are often not considered for differential diagnosis. ${ }^{3}$ In our case, only one patient was suspected of having nerve sheath tumor because of earlier experience (Table 2). In vagal schwannomas, clinical sign elicited is paradoxical cough on palpating the mass which was present in our case. ${ }^{10}$ In head and neck schwannomas, $10 \%$ are from vagal and cervical sympathetic nerve. ${ }^{11}$ In our series, three patients were from vagus nerve (30\%) and four patients from sympathetic nerve (30\%).

Radiological investigation is helpful in the diagnosis of spindle cell neoplasm from other tumors like carotid body tumors, paragangliomas, and vallecular cyst. CT scan/MRI scan is helpful in differentiating schwannomas from others. These investigation can also be helpful to know the NOO of schwannomas.

On CT scan, these masses showed as soft tissue mass with homogenous contrast enhancement. In big schwannomas, changes such as cystic degeneration associated with mucinous degeneration were noted as heterogeneous enhancement on

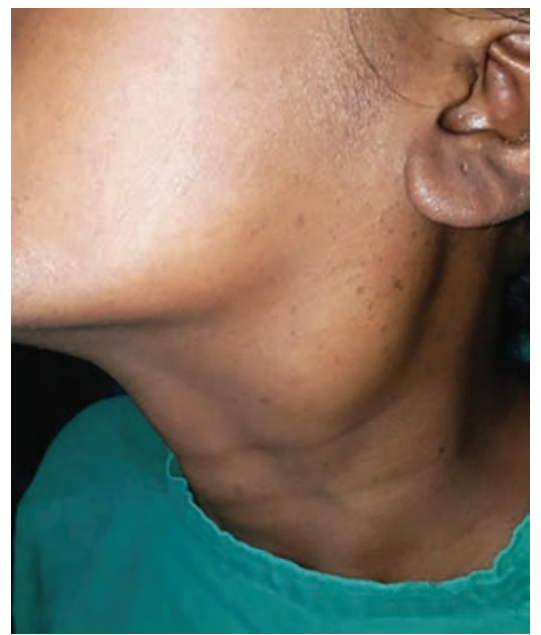

Fig. 2: Common presentation of schwannoma in the neck
CT scan. ${ }^{12}$ Preoperatively CT scan is helpful in differentiating vagal schwannoma from sympathetic schwannomas.

From anatomical aspect, the carotid sheath contains the carotid artery, the internal jugular vein, and vagus nerve. The carotid sympathetic ganglion descends medioposterior aspect to the carotid sheath.

Accordingly, when vagal schwannomas enlarge, the internal jugular vein is displaced laterally and carotid artery is displaced medially with separation of carotid and internal jugular vein (IJV). In contrast, when a sympathetic schwannoma is enlarged, the carotid sheath is displaced anterolaterally not displacing the internal jugular vein and carotid artery. On CT scan, the displacement of the major vessels can be made out to diagnose vagal and sympathetic schwannomas. ${ }^{12}$ Figure 4 shows CT scan of vagal and sympathetic schwannomas.

In our case series, all sympathetic schwannomas are distinguished from vagal schwannoma on CT scan. MRI scan is a better option than CT scan if it is available. In our cases series, none of them had MRI scan because patients had already undergone CT scan. If the tumor is from small sensory nerve, origin could not be made out by clinical diagnosis. Ultrasound is a cost-effective modality investigation, but specific signs of schwannomas such as split fat sign, fascicular sign, and target sign can be well appreciated along with $\mathrm{NOO}$ in MRI scan. In our study, NOO can be made out in six cases $(60 \%)$. The FNAC is still controversial; the majority of the authors do not recommend open or needle biopsy for those masses $^{3}$ because of the difficulties arise rises during complete excision of the tumor. In our cases, FNA showed spindle neoplasm in five cases (50\%), and inconclusive in four cases. In one case (patient no. 9) incisional biopsy was done after tracheostomy because of large laryngeal schwannoma. Hence, FNAC is conclusive in five cases. FNAC is a better option than incisional biopsy, and it should be done after radiological investigation (CT/MRI scan) to rule out carotid body tumor/paragangliomas.

FNAC is based on characteristic Antoni A and Antoni B. Antoni $A$ areas are composed of interlacing bundles of spindle cells (Schwann cells) with wavy or oval nuclei, eosinophilic cytoplasm, and indistinct cytoplasmic borders. Intranuclear vacuoles may be present. Antoni B areas are hypocellular and less compact than Antoni A areas. They consist of haphazardly arranged spindle cells in a loose myxoid or hyalinized stroma containing a few
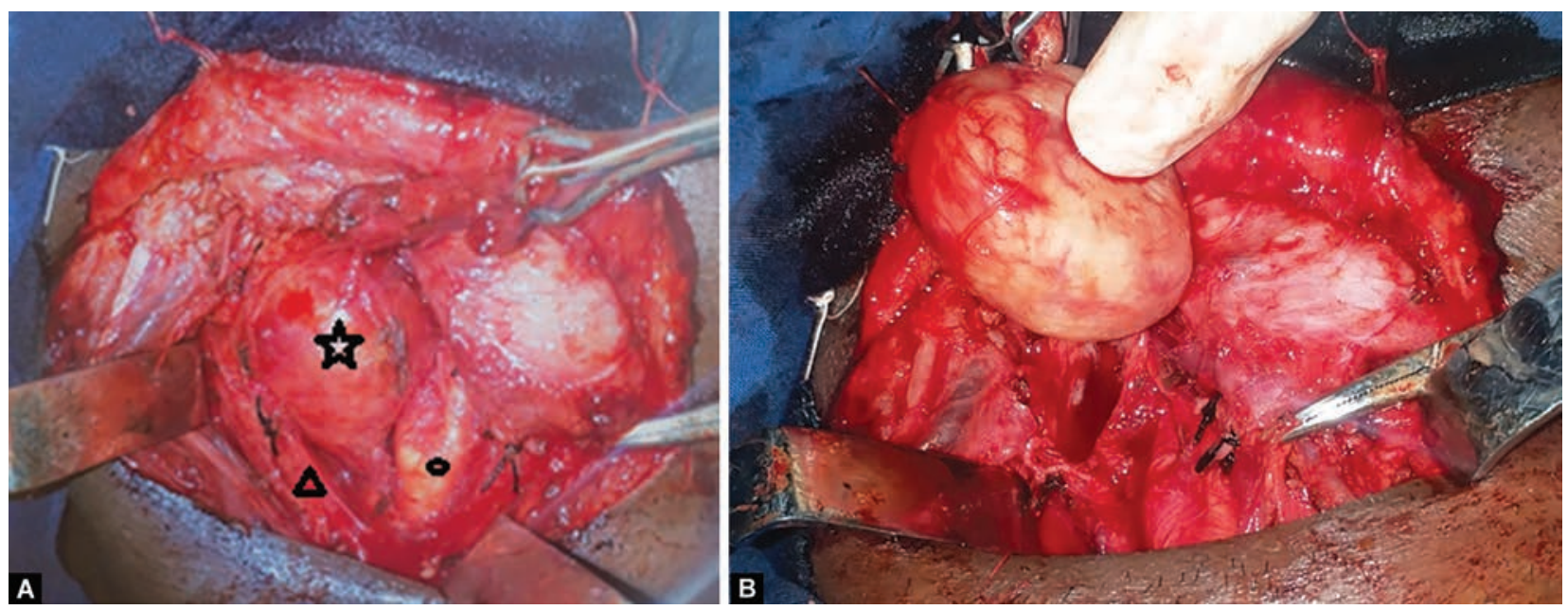

Figs 3 A and B: Sympathetic schwannoma (star: tumor, dot: carotid artery, triangle: IJV) 

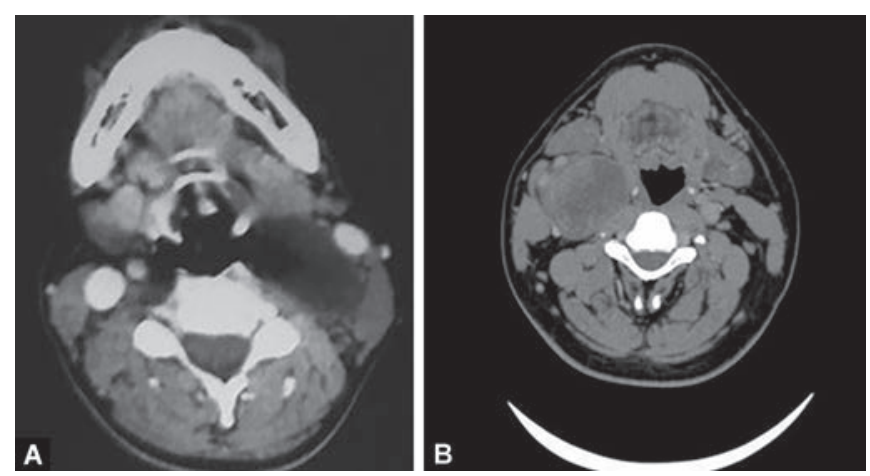

Figs 4A and B: CT scan showing: (A) Sympathetic schwannoma; (B) Vagal schwannoma

inflammatory cells and delicate collagen fibers. Thus features of degeneration, hemorrhage and necrosis may co-exist if the tissue is more in size.

Otherwise, in antoni B area tissue is loosely arranged stroma cells and fibers show no distinct form. Thus features of degeneration, hemorrhage, and necrosis may coexist, if the tissue is more in size.

Schwannoma are resistant to radiotherapy. Hence, treatment of all schwannomas is complete surgical excision with possible preservation of NOO. Surgical modality could be complete excision and nerve grafting, intracapsular dissection of the tumor, or debulking of the tumor. The main aim of the treatment is excision of the tumor with minimizing the postoperative neurological deficit.

In the study by Liu et al., ${ }^{5}$ the rate of nerve palsy after operation were $100 \%, 67 \%$, and $50 \%$ for resection with division of NOO, intracapsular enucleation, and debulking of the tumor, respectively. Hence intracapsular dissection does not guarantee the preservation of $\mathrm{NOO}$, if the tumor is large.

In intracapsular enucleation, minimum longitudinal incision over the capsule was made. When the tumor was removed after making an incision, additional damages around the tumor did not occur. When the tumor was not isolated from the capsule, I used finger to dissect the tumor so that intensity is maintained. Preoperatively NOO was made out in seven cases (70\%). It corelated with preoperative diagnosis in NOO.

In our case series, one patient had left vagal palsy even after anastomosis of remnant vagal fibers. None of the other patients had neurological deficit.

In our case series follow up was done for 2-3 years. Recurrence of the tumor is less in total resection of the tumor. According to zbaren et al, there was no significant difference in the recurrence rate between total resection including nerve fibre and intracapsular enucleation. In case of debulking of the tumor, recurrence rate has been reported to rise. ${ }^{13}$ In our study mean follow up was 2.5 years and there was recurrence.

Transformation of malignant from benign tumor schwannomas are not available in the literature. A review on intracranial malignant peripheral nerve sheath tumor (MPNST) suggested that most of the MPNST are developed sporadically rather than transforming from benign tumor. ${ }^{2}$ Current knowledge showed that most MPNSTs are associated with neurofibromatosis type 1 .

\section{Conclusion}

Head and neck schwannomas are rare neoplasms which are considered as one of the differential diagnosis of neck swelling. Diagnosis of schwannoma is established by clinical suspicion, FNAC, and radiological imaging. FNA to be done after CT/MRI scan to rule out paragangliomas. Sympathetic and vagal schwannomas can be diagnosed depending upon the displacement of carotid artery and internal jugular vein. Nerve of origin cannot be made out in all cases except if it arises from major nerves. Postoperative neurological deficit will be present even when surgery is done through intracapsular dissection. Hence postoperative neurological deficit is explained to the patients and patients' attenders. Further study is needed to preserve the functional integrity of NOO after excision of the tumor by intracapsular dissection.

\section{References}

1. Kumar AB, Rajan P. Schwannoma of the tongue: a case report. Calicut Med J 2004;2(2):e4. DOI: 10.1016/j.ooe.2004.09.003

2. Ducatman BS, Scheithauer BW, Piepgras DG, et al. Malignant peripheral nerve sheath tumors. A clinicopathologic study of 120 cases. Cancer 1986 15;57(10):2006-2021. DOI: 10.1002/1097-0142(19860515)57:10<2006::aid-cncr2820571022> 3.0.co;2-6

3. Colreavy MP, Lacy PD, Hughes J, et al. Head and neck schwannomas - a 10 year review. J Laryngol Otol 2000;114(2):119-124. DOI: 10.1258/0022215001905058

4. Zhang H, Cai C, Wang S, etal. Extracranial head and neckschwannomas: a clinical analysis of 33 patients. Laryngoscope 2007;117(2):278-281. DOI: 10.1097/01.mlg.0000249929.60975.a7

5. Liu HL, Yu SY, Li GK, et al. Extracranial head and neck schwannomas: a study of the nerve of origin. Eur Arch Otorhinolaryngol 2011; 268(9):1343-1347. DOI: 10.1007/s00405-011-1491-4

6. Haider M, Rahim M, Bashar NM, Hossain M, Islam SM. Schwannoma of the Base of the Tongue: A Case Report of a Rare Disease and Review of Literatures. Case Reports in Surgery. 2020 Dec 29;2020. DOI: 10.1155/2020/7942062

7. Sharma DK, Sohal BS, Parmar TL, et al. Schwannomas of head and neck and review of literature. Indian J Otolaryngol Head Neck Surg 2012;64(2):177-180. DOI: 10.1007/s12070-011-0248-0

8. Jadwani S, Bansod S, Mishra B. Intraoral schwannoma in retromolar region. J Maxillofac Oral Surg 2012;11(4):491-494. DOI: 10.1007/s12663-010-0100-1

9. Gosk J, Gutkowska O, Kulinski S, et al. Multiple schwannomas of the digital nerves and superficial radial nerve: two unusual cases of segmental schwannomatosis. Folia Neuropathol 2015;53(2):158-167. DOI: $10.5114 / f n .2015 .52413$

10. Gilmer-Hill HS, Kline DG. Neurogenic tumors of the cervical vagus nerve: report of four cases and review of the literature. Neurosurgery 2000;46(6):1498-1504. DOI: 10.1097/00006123-200006000-00036

11. Ozlugedik S, Ozcan M, Unal T, et al. Cervical sympathetic chain schwannoma: two different clinical presentations. Tumori J 2007;93(3):305-307. DOI: 10.1177\%2F030089160709300316

12. Furukawa M, Furukawa MK, Katoh K, et al. Differentiation between schwannoma of the vagus nerve and schwannoma of the cervical sympathetic chain by imaging diagnosis. Laryngoscope 1996;106(12):1548-1552. DOI: 10.1097/00005537-199612000-00021

13. Zbäuren P, Markwalder R. Schwannoma of the true vocal cord. Otolaryngology-Head and Neck Surgery. 1999 Dec;121(6):837839. DOI: 10.1053\%2Fhn.1999.v121.a99282 